PUBLISHER CORRECTION

\title{
Correction to: Robust Arbitrage Conditions for Financial Markets
}

\section{Derek Singh $^{1} \mathbb{D} \cdot$ Shuzhong Zhang ${ }^{1}$}

Published online: 11 August 2021

๑) Springer Nature Switzerland AG 2021

\section{Correction to: Operations Research Forum https://doi.org/10.1007/s43069-021-00073-0}

The original article unfortunately was published with the name of Shuzhong Zhang incorrectly spelled as Shuzong Zhang. Also, the formulation of Theorem 2.1 and 3.2 had some errors.

The original article has been corrected.

The original article can be found online at https://doi.org/10.1007/s43069-021-00073-0.

Derek Singh

singh644@umn.edu

Shuzhong Zhang

zhangs@umn.edu

1 University of Minnesota, Minneapolis, MN, USA 